\title{
Pengujian Aplikasi Reservasi Hotel di LeGreen Hotel \& Suite dengan Metode Black Box Testing Boundary Value Analysis
}

\author{
Achmad Yani ${ }^{1}$, Deny Setiawan ${ }^{2}$, Novrizal Egi ${ }^{3}$, Rizky Subagja ${ }^{4}$, Teti Desyani ${ }^{5}$ \\ Teknik Informatika, Universitas Pamulang, Tangerang Selatan, Banten, Indonesia \\ E-mail: 1achmadyani1901@gmail.com, ${ }^{2}$ denys@gmail.com, ${ }^{3}$ novrizalegi@gmail.com, \\ ${ }^{4}$ rizkysubagja98@gmail.com, ${ }^{5}$ dosen00839@unpam.ac.id
}

Submitted Date: March 21 $1^{\text {st }}, 2020$
Revised Date: April 06 ${ }^{\text {th }}, 2020$

\begin{abstract}
In this test we will use software that has been made, namely the desktop-based LeGreen Hotel Reservation Application. In testing this hotel room reservation application, the writer uses the black box testing method. Black Box Testing is suitable in testing hotel booking applications because this test aims to ensure the functionality of the LeGreen Hotel Reservation application. This study has several stages that must be done, including the identification of experimental problems, input data samples into the process system, then testing to evaluate the output and finally the documentation of test results. Based on the analysis of the results of the application of methods to solve the problem shows that the level of application that runs reaches $70 \%$, able to run and process employee data, rooms, visitors and payments used for hotel reservations. In the admin login form of $30 \%$, only $20 \%$ succeeded, and in the Print Report Form, repairs are needed in order to improve the quality of the application in processing report print data as it functions.
\end{abstract}

Keywords: Hotel Reservation Application; Black Box Testing; Boundary Value Analysis

Abstrak

Dalam pengujian ini kami akan menggunakan software yang telah dibuat yaitu Aplikasi Reservasi Hotel LeGreen berbasis desktop. Dalam pengujian aplikasi pemesanan kamar hotel ini penulis menggunakan metode black box testing. Black Box Testing cocok dalam pengujian aplikasi pemesanan kamar hotel karna pengujian ini bertujuan untuk memastikan fungsionalitas dari aplikasi reservasi Hotel LeGreen. Penelitian ini memiliki beberapa tahapan yang harus dilakukan, diantaranya yaitu Identifikasi masalah percobaan, input data sample kedalam system proses, selanjutnya pengujian melakukan evaluasi pada output dan yang terakhir dokumentasi hasil uji. berdasarkan analisa hasil penerapan metode untuk menyelesaikan masalah menunjukkan bahwa tingkat aplikasi yang berjalan mencapai $70 \%$, mampu menjalankan dan mengolah data karyawan, kamar, pengujung serta pembayaran yang digunakan untuk keperluan reservasi di hotel. Dalam form login admin dari $30 \%$ hanya $20 \%$ berhasil dan pada Form Cetak Laporan diperlukan perbaikan kembali guna untuk meningkatkan kualitas aplikasi dalam mengolah data cetak laporan sebagai mana fungsinya.

Kata Kunci: Aplikasi Reservasi Hotel; Black Box Testing; Boundary Value Analysis

\section{Pendahuluan}

Dalam proses pembuatan perangkat lunak pastinya kita akan mengalami "bug" atau mengalami kesalahan "error" pada tahap-tahap tertentu. Untuk menjamin software yang dihasilkan telah bebas dari kesalahan umumnya dilakukan dengan pengujian yang merupakan tahapan paling mahal dalam pengembangan software (Saifudin \& Yulianti, 2020). Agar terhindar dari bug yang terlalu banyak maka dibutuhkan pengujian perangkat lunak yang sudah dibuat untuk pelanggan atau masih terus dalam tahap pengembangan. Maka dari itu pengtingnya melakukan pengujian perangkat lunak berdasarkan pada kualitas perangkat lunak tersebut.

Dengan adanya perkembangan teknologi yang semakin modern dari masa ke masa, 
membuat banyaknya hotel-hotel melakukan sistem pemesanan kamar dengan memanfaatkan fasilitas internet. Dikarenakan metode ini memiliki banyak keuntungan yang bisa diperoleh dabandingkan dengan melakukan pemesanan kamar dengan sistem pemesanan secara langsung.

Dalam pengujian ini kami akan menggunakan software yang telah dibuat yaitu Aplikasi Reservasi Hotel LeGreen berbasis desktop. Dalam aplikasi ini awalnya kita masuk ke form login, di dalamnya form tersebut ada pengisian username dan password yang akan dilakukan karyawan, lalu masuk kedalam form kamar dan pengunjung, setelah itu kita bisa masuk ke form harga untuk memasukan jumlah harga total, selanjutnya selesai transaksi, karyawan akan mencetak bukti pembayaran kamar hotel tersebut.

Pengujian software bertujuan untuk menilai apakah perangkat lunak yang dikembangkan sudah memenuhi kebutuhan pengguna. Pengujian mencakup proses menemukan kesalahan dan memperbaikinya sehingga sistem dikatakan layak untuk digunakan (Nurudin, Jayanti, Saputro, Saputra, \& Yulianti, 2019). Melakukan penilaian apakah tahap pengembangan perangkat lunak sudah sesuai dengan metodologi yang dipakai. Membuat dokumentasi hasil pengujian yang di dalamnya menginformasikan kesesuaian perangkat lunak yang diuji dengan spesifikasi yang telah ditentukan. Sehingga sangat perlu untuk melakukan pengujian untuk mengurangi terjadinya kesalahan yang merugikan tersebut (Ningrum, Suherman, Aryanti, Prasetya, \& Saifudin, 2019).

Dalam pengujian aplikasi pemesanan kamar hotel ini penulis menggunakan metode black box testing guna untuk memastikan user interface serta fungsi aplikasi berjalan baik serta menjamin pengalaman penggunaan user yang lebih baik. Black Box testing mencakup pengujian user interface, input, serta output dari sistem. Black Box Testing cocok dalam pengujian aplikasi pemesanan kamar hotel karna pengujian ini bertujuan untuk memastikan fungsionalitas dari aplikasi Reservasi Hotel LeGreen.

Menguji User Interface Aplikasi reservasi kamar hotel apakah berfungsi sebagai mana mestinya. Memastikan Aplikasi reservasi kamar hotel dapat berfungsi sebagai mana mestinya

\section{Metodologi}

Aplikasi Reservasi Hotel LeGreen berbasis desktop merupakan sistem informasi yang bertujuan untuk memberikan informasi tentang pemesanan kamar di hotel LeGreen. Sistem informasi adalah kumpulan dari sub-sub sistem yang saling terintegrasi dan berkolaborasi untuk menyelesaikan masalah tertentu dengan cara mengolah data sehingga memiliki nilai tambah dan bermanfaat bagi pengguna (Taufiq, 2018). Aplikasi Reservasi (pemesanan) adalah aplikasi yang digunakan oleh para pemesan ruangan (Isnawaty, Liyata, \& Subardin, 2016) untuk mendapatkan informasi kondisi kamar, melihat ketersediaan, dan melakukan pemesanan.

Pada pengujian aplikasi digunakan teknik black box yang memiliki arti bahwa pengujian yang dilakukan hanya mengambil hasil eksekusi melalui data uji dan memeriksa fungsional dari perangkat lunak (Krismadi, et al., 2019). Berikut ini beberapa teori pendukung yang digunakan:

\section{A. Blackbox Testing}

Blackbox Testing yaitu salah satu teknik pengujian perangkat lunak yang fokusnya pada spesifikasi fungsional dari perangkat lunak. Dengan adanya Balckbox Testing memungkinkan pengembang perangkat lunak untuk membuat kumpulan suatu keadaan input pada suatu program yang akan melatih seluruh syarat-syarat fungsionalnya.

Ada beberapa Keuntungan menggunakan perangkat lunak dengan metode Blackbox Testing yaitu :

1. Penguji tidak harus mempunyai pengetahuan yang khusus tentang bahasa pemograman.

2. Pengujian ini membantu untuk mengungkapkan ambigulitas atau inkonsistensi dalam spesifikasi persyaratan, yang jika dilihat dari sudut pandang penggunaan,

3. Programmer dan Tester memiliki ketergantungan satu sama lain.

Selanjutnya ada beberapa kekurangan dalam metode Blackbox Testing yaitu :

1. Adanya kesulitan Uji kasus tanpa spesifikasi yang jelas

2. Adanya Kemungkinan pengulangan tes yang sudah dilakukan oleh Programmer. 
B. Boundary Value Analysis

Boundary Value Analysis merupakan suatu teknik blackbox testing yang pengujiannya dilakukan pada batas atas dan batas bawah nilai yang diisikan pada aplikasi (Ijudin \& Saifudin, 2020). Ada beberapa prinsip yang mendasari boundary value analysis (BVA) di antaranya:

1. Sering terjadinya kesalahan pada masukan (input).

2. BVA memberikan ijin untuk menyeleksi kasus uji yang di dalamnya menguji batasan nilai input.

BVA merupakan komplemen dan equivalence partitioning. Maksudnya lebih kepada memilih elemen-elemen yang ada pada bagian sisi batas dari kelas ekivalen tersebut.

C. Alur Penelitian

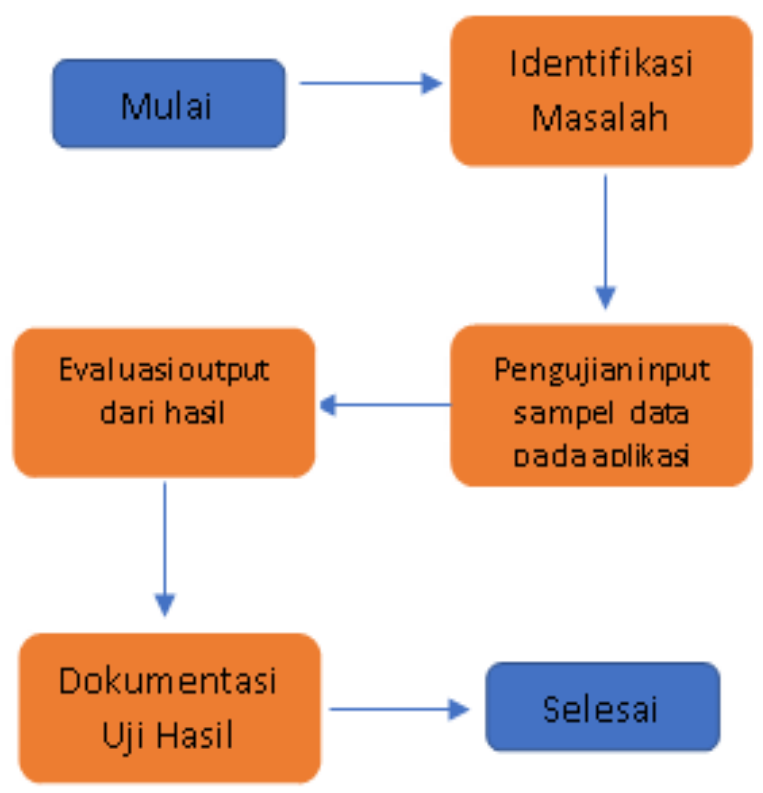

Gambar 1 Alur penelitian

Penelitian ini memiliki beberapa tahapan yang harus dilakukan, diantaranya yaitu Identifikasi masalah percobaan, input data sample kedalam system proses, selanjutnya pengujian melakukan evaluasi pada output dan yang terakhir dokumentasi hasil uji. Alur penelitian dapat dilihat pada diagram Gambar 1.

Berikut Form Login Page yang ditampilkan pada Menu ketika Login :

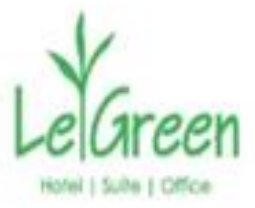

LOGIN PAGE

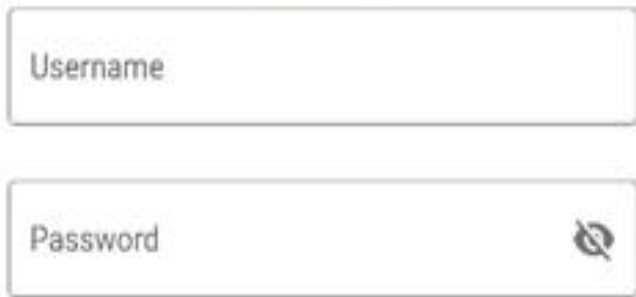

Forgot Passworo

MASUK

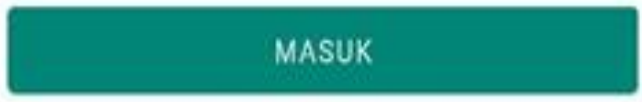

Register Here

Gambar 2 Form login

\section{Hasil dan Pembahasan}

Hasil penerapan metode pengujian dan analisanya menggunakan metode BlackBox yang digunakan dalam pengujian aplikasi reservasi berbasis dekstop. Aplikasi ini sangat berguna untuk membuat beberapa fungsi dan modul, sebagai contoh yang yang akan di bahas dalam pengujian aplikasi tersebut. Fungsi yang akan kita bahas dari Form Login Admin, Menu Pengunjung, Menu Karyawan, Menu Kamar, Menu Pembayaran dan Menu Cetak Laporan. 
Tabel 1 Pengujian Form Login Admin

\begin{tabular}{|l|l|l|l|}
\hline \multicolumn{1}{|c|}{ Deskripsi Pengujian } & \multicolumn{1}{c|}{ Hasil yang diinginkan } & \multicolumn{1}{c|}{ Hasil Uji } & Kesimpulan \\
\hline $\begin{array}{l}\text { Masukkan ID pada Form } \\
\begin{array}{l}\text { Login Page dengan } \\
\text { Username dan Password } \\
\text { dikosongkan }\end{array}\end{array}$ & $\begin{array}{l}\text { Akses Login ditolak oleh } \\
\text { system dan muncul tampilan } \\
\text { "Username dan Password harus } \\
\text { diisi" }\end{array}$ & $\begin{array}{l}\text { Login ditolak oleh } \\
\text { system tetapi pesan } \\
\text { yang ditampilkan adalah } \\
\text { "idkaryawan invalid" }\end{array}$ & failed \\
\hline $\begin{array}{l}\text { Masukkan ID pada Form } \\
\text { Login Page dengan }\end{array}$ & $\begin{array}{l}\text { Akses Login ditolak oleh } \\
\text { system dan muncul tampilan } \\
\text { "Username dan Password } \\
\text { yg tidak terdaftar }\end{array}$ & $\begin{array}{l}\text { Login ditolak oleh } \\
\text { system tetapi pesan } \\
\text { Terdaftar" }\end{array}$ & Failed Password Tidak ditampilkan adalah \\
"idkaryawan not found" & \\
$\begin{array}{l}\text { Masukkan ID pada Form } \\
\text { Login Page dengan }\end{array}$ & $\begin{array}{l}\text { Proses diterima dan masuk ke } \\
\text { tampilan Menu Utama } \\
\text { yang sudah terdaftar }\end{array}$ & $\begin{array}{l}\text { Proses diterima dan } \\
\text { masuk ke tampilan } \\
\text { Menu Utama }\end{array}$ & Success \\
\hline
\end{tabular}

Tabel 2 Pengujian Menu Karyawan

\begin{tabular}{|l|l|l|l|}
\hline Deskripsi Pengujian & Hasil yang Diinginkan & Hasil Uji & Kesimpulan \\
\hline $\begin{array}{l}\text { Mencoba Input } \\
\text { Karyawan Baru }\end{array}$ & $\begin{array}{l}\text { Sistem sukses input data } \\
\text { karyawan dan memuat ulang } \\
\text { form karyawan }\end{array}$ & $\begin{array}{l}\text { Sistem sukses input data } \\
\text { karyawan dan memuat ulang } \\
\text { form karyawan }\end{array}$ & Success \\
\hline $\begin{array}{l}\text { Mencoba melihat data } \\
\text { karyawan yang sudah } \\
\text { di input. }\end{array}$ & $\begin{array}{l}\text { Muncul tabel karyawan } \\
\text { dengan data yang sudah } \\
\text { pernah di input }\end{array}$ & $\begin{array}{l}\text { Muncul tabel karyawan } \\
\text { dengan data yang sudah } \\
\text { pernah di input }\end{array}$ & Success \\
\hline $\begin{array}{l}\text { Mencoba menghapus } \\
\text { data karyawa }\end{array}$ & $\begin{array}{l}\text { Pilih data yang aka dihapus } \\
\text { lalu form akan langsung } \\
\text { merefresh tampilan tanda data } \\
\text { sudah dihapus }\end{array}$ & $\begin{array}{l}\text { Pilih data yang akan dihapus } \\
\text { lalu form akan langsung } \\
\text { merefresh tampilan tanda } \\
\text { data sudah dihapus }\end{array}$ & Success \\
\hline
\end{tabular}

Pengujian mencakup proses verifikasi dan melakukan perbaikan software. Ketika dilakukan pengujian ditemukan 2 perbedaan hasil yang diharapkan pada form login admin. Perbedaan ini langsung diperbaiki sehingga setelah pengujian semua sudah sesuai harapan. Dengan dilakukan pengujian dapat menjamin bahwa semua persyaratan pengembangan software telah terpenuhi.

\section{Kesimpulan}

Kesimpulan berdasarkan analisa hasil penerapan metode untuk menyelesaikan masalah menunjukkan bahwa tingkat aplikasi yang berjalan mencapai $70 \%$, mampu menjalankan dan mengolah data karyawan, kamar, pengujung serta pembayaran yang digunakan untuk keperluan reservasi di hotel. Dalam form login admin dari $30 \%$ hanya $20 \%$ berhasil dan pada Form Cetak Laporan diperlukan perbaikan kembali guna untuk meningkatkan kualitas aplikasi dalam mengolah data cetak laporan sebagaimana fungsinya.

\section{Saran}

Dengan adanya penelitian ini disarankan untuk peneliti selanjutnya agar mencari dan membaca referensi lebih banyak lagi serta melakukan penelitian yang lebih dalam lagi mengenai Metode BlackBox Testing Boundary Value Analysis sehingga hasil penelitian selanjutnya akan semakin baik. Dan diharapkan penelitian ini bisa dijadikan sebagai bahan rujukan bagi penelitian selanjutnya.

\section{Referensi}

Isnawaty, I., Liyata, M. L., \& Subardin, S. (2016). Rancang Bangun Aplikasi Penjadwalan Ruang Meeting Hotel Menggunakan Algoritma Multiple Feedback Queue (MFQ) Berbasis Android Menggunakan Layanan SMS “Studi Kasus Hotel Plaza Inn Kendari”. semanTIK, 189-196. 
Jaya, T. S. (Januari 2018). Pengujian Aplikasi dengan Metode Blackbox Testing. Jurnal Informatika: Jurnal Pengembangan IT (JPIT), Vol.03, No.02, .

Krismadi, A., Lestari, A. F., Pitriyah, A., Mardangga, I. W., Astuti, M., \& Saifudin, A. (2019). Pengujian Black Box berbasis Equivalence Partitions pada Aplikasi Seleksi Promosi Kenaikan Jabatan. Jurnal Teknologi Sistem Informasi dan Aplikasi, 2(4), 155-161.

Ningrum, F. C., Suherman, D., Aryanti, S., Prasetya, H. A., \& Saifudin, A. (2019). Pengujian Black Box pada Aplikasi Sistem Seleksi Sales Terbaik Menggunakan Teknik Equivalence Partitions. Jurnal Informatika Universitas Pamulang, 4(4), 125-130.

Nurudin, M., Jayanti, W., Saputro, R. D., Saputra, M. P., \& Yulianti, Y. (2019). Pengujian Black
Box pada Aplikasi Penjualan Berbasis Web Menggunakan Teknik Boundary Value Analysis. Jurnal Informatika Universitas Pamulang, 4(4), 143-148.

Saifudin, A., \& Yulianti, Y. (2020). Dimensional Reduction on Cross Project Defect Prediction. Journal of Physics: Conference Series. 1477, hal. 022030. Tangerang: IOP Publishing. doi:10.1088/17426596/1477/3/032011

Taufiq, R. (2018). Pengantar Sistem Informasi. Jakarta: Mitra Wacana Media. 